branch of the Samaritan Hospital, entered into a curious calculation, and showed the total gain of life of the 373 survivors of my first 500 operations to be " 10,817 years of average healthy life, instead of the I,492 years of miserable endurance which they might have passed before death without operation". Of the 400 patients operated on since the 500, 306 are cured, making the total recoveries 679. Multiplying this number by 29 years, the average estimated gain of each patient, the total gain amounts to 19,691 years. I submitted the basis of Lord Selborne's calculation to Dr. William Farr, thinking possibly there might be some fallacy which I had not detected. Dr. Farr confirmed its complete accuracy, and it is a very simple piece of multiplication. The average age of the patients was as nearly as possible thirty-eight years. At this period, the Carlisle Tables assign, as the expectation of life for a healthy woman in this country, twenty-nine years; so that one has simply to multiply the number of survivors by twenty-nine. Had the women not been operated upon, it would be a very liberal allowance to estimate their average expectation at four years; and Lord Selborne, speaking of the addition to life to each of the women successfully operated upon, has calculated twenty-five years as clear or absolute gain. He said: "Instead of the four years of declining health and hopeless misery which these women would have had to anticipate, not only those four years, but twenty-five years, which upon the average had been wholly saved to them, were years of restored health, usefulness, and happiness."

\section{PATHOLOGICAL MEMORANDA.}

\section{OBLITERATIVE ENDARTERITIS.}

THE interesting article on obliterative endarteritis in the JOURNAL of June 29th shows a disposition to abandon the pathological significance of that form of syphilitic arteritis with which the name of Heubner more especially is associated. Whatever be the final outcome of the observations of Friedländer, Koster, and Baumgarten, there seems to be reason, at the present juncture, to avoid a too ready rejection of all the cases of syphilitic arterial disease described of late years. Certainly there are a number of cases in which the evidence of the syphilitic nature of the (primary) arterial disease is of the very strongest.

When a patient dies of syphilitic disease the lesions of which, in a typical form, are strewn throughout the body, and are associated only (if at all) with such other pathological conditions as are evidently of a secondary nature, and when the morbid changes of the arteries have the same forms as the syphilitic lesions in other systems of the body, it is difficult to deny the syphilitic nature of the vascular changes. Of such character were two cases described by myself in the first of a series of papers in the British and Foreign Medico-Chirurgical Revieze (July 1876, p. 161 ), under the following headings.

CASE I (loc. cit., p. I63).-- "Dementia; physical signs simulating general paralysis; headache ; epileptiform attacks ; transitory hemiplegia ; recurrence of the epileptiform convulsions, assuming an excessively violent form, and occurring in rapid succession; death in the 'stalus'. Syphilitic disease of the brain, cerebral arteries, spleen, liver, skin, and testis."

CASE II (p. 174).- " Sudden attack of paresis of articulation and deglutition, and of incomplete right hemiplegia, followed by intellectual and moral deterioration, and by temporary attacks of dysphagia with vaso-motor disturbance. Subsequently, dementia; incomplete right hemiplegia; speechlessness; intestinal torpor; contraction of limbs; extensive disease of cerebral arteries; gumma of left corpus striatum" [and gumma of liver].

But, besides these naked-eye changes, the microscope revealed in both cases a more or less extensive alteration in the minute arteries of the brain. Only the most obvious of the microscopical appearances were described, and that very briefly. Among the less obvious and extensive of the changes noted was an indistinct cellular proliferation in the inner coats of some. The gummata of the large basal arteries were in an advanced stage; and undoubtedly the appearances vary very much with the particular stage of the morbid change at which death happens to take place.

Finally, in the third paper of the above mentioned series (April 1877, p. 444), it was indicated that these cases of syphilitic disease of the cerebral arterioles as well as arteries include many, if not all, of the very cases in which intracranial syphilitic disease most closely simulates general paralysis of the insane; and further experience confirms me in that opinion.

\section{W. Julius Mickle, Grove Hall Asylum, London.}

\section{AN ADDRESS}

\section{SOME EFFECTS OF THE CLIMATE OF TORQUAY. \\ Delivered at the Annual Meeting of the South- Western Branch.}

By C. R A D C L F F E H A L L, F.R.C.P, Consulting-Physician to the Torquay Hospital for Consumption; Presi ent of the Branch; etc.

Gentlemen,-My first duty is the very pleasant one of giving you all a hearty welcome from myself and my fellow medical men of this town. And in this Torquay is beforehand with me, for she has put on a smiling face to receive you. Were you strangers from the other end of the country, I might feel it right to point out to you the beauties of this neighbourhood and the medical peculiarities of this climate; but, as you are all west countrymen, you know sufficiently well what I could say on this head. I will content myself with occupying your attention for a very short time by saying what $I$ can in reference to the demerits of Torquay in a medical point of view. In a picturesque sense, I need only say, "If you want a proof of that, look around". Now, what do we ever hear at a distance against the climate of Torquay? It is summed up in a word-" It is so relaxing!" How stands the fact? Is Torquay what is meant by relaxing? It is ; and it is not. When the wind sets off the sea from the south or south-west, it is so; but, when the winds sets off the land, north, north-west, due west, north-east, and due east, it is not. A word largely governs opinion, particularly a depreciatory word. What, then, is the meaning of this word relaxing? It means a place where a healthy person feels more languid, less energetic, less up to the mark than elsewhere. It means temporarily enervating, but it is often misunderstood to mean permanently debilitating. It cannot be this, for it is in the experience of everyone that any feeling of languor due to the climate of Torquay disappears in twenty-four hours after going a hundred miles inland, and leaves no diminution of strength or vigour behind. And it is not every person in health who complains of Torquay as proving relaxing. Those of robust sanguine temperament, who are apt to err on the side of overenergy, find themselves here in a state of happy and comfortable calm and quiet strength.

But it is not of healthy persons we are now thinking. They may afford to be guided by their feelings of what is most pleasant to them at the onset, and place their residence anywhere. But for the pulmonary invalid this is not so. He ought not to trust to what he feels on a short acquaintance; he must be guided by the practical results of a longer experience. One's feelings on a short acquaintance are often misleading. On the first day of a bright still frost, with a sunny sky, all-healthy animals rejoice in the bounding energy they feel to pervade their system. And the pulmonary invalid, as a rule, likes it too. But for how long? For just so long as he does not feel the ill effects of the cold. And how does cold occasion ill effects? By inducing inflammation. For pulmonary invalids, we want a safe, not an exciting, climate. For what is the especial source of danger in pulmonary disease? Inflammation. Whether the case originated in inflammation, as many do, or not-and many do not-yet, in all alike the occurrence of inflammation is what we dread, its persistence is what we oppose, its disappearance what we hail with hope and pleasure. It is inflammation which opposes Nature in her various modes of cure; it is inflammation which quickens the downward progress of the disease; and it is the consequence of unarrested inflammation which kills.

Let us remind ourselves in simple terms what this all-important condition is. When any part of a living body is from any cause unable to nourish itself, it either dies at once or inflames; unable to feed itself, it is unable to discharge its functions; it strikes work. The rest of the organism may be supposed to say : "If you do not fulfil your duties in the economy, we shall either alter you, so that you can again do your work, or remove you. We, the capitalists who supply you with food and power, cannot look upon you as a brick in a house, which may undergo injury whilst the remainder of the structure sustains none, but in this living structure all is so knitted together, so interdependent, that if one component part suffers, all suffer." Now, the commoner causes of inflammation are mechanical injury, the presence of a foreign body, and cold. If you get a thorn in your hand, it divides living texture, and is 
so far a mechanical injury ; and, if it remain, it acts as a foreign body. Inflammation is set up around it, and either leads to expulsion of the thorn, or it may cause lymph to be thrown out around the thorn, which may cut it off from the sensitive surrounding tissues, and sheathe it, as it were, in a case of fine leather, and so prevent it from making further irritation; and the inflammation subsides, although the foreign body remains, but now as an mnocent resident only-as likewise might happen to an encysted shot, or an undisintegrated tubercle in the lungs. The thorn, of course, prenents at first the injured part from being able to nourish itself, and, therefore, from being able to discharge its proper work. Next, let us think of a chilblain; inflammation induced by cold. Cold contracts a piece of iron; cold contracts everything; and cold contracts the blood-vessels of a part, so that the blood cannot get through them. When a delicate lady's finger "dies" from washing her hands in cold water on a frosty morning, we have an illustration of cold quite stopping circulation. When a person is unable to keep himself warm, less oxygen passes through the lungs into his blood, the cheeks are shrunken and pale, and the lips blue. In frost-bite, if heat be rapidly applied, we have sudden inflammation set up so severe as to kill the part. A less degree of cold will make the fingers of a person with languid circulation swelled, purpde, and numb. Therefore, we see that cold tends to slacken the circulation, it contracts the vessels so that they admit less blood, and what they do admit tends to stagnate ; it at the same time stops the part from nourishing itself for the moment, and that it stops it from performing its duties is shown by its effects upon the nerves, by the numbness or complete insensibility, as well as by the tingling unpleasant sensations of slowly restored warmth. This influence more gently, but more continuously, applied to the surface makes the skin inflame, and this is chilblain. Now, if in your hand you had at the same time a chilblain, induced by cold, and a thorn in the flesh, you would typify before your eyes what occurs in a delicate lung when the invalid is exposed to culd. The thorns in the flesh are the already existing seeds of disease which tend to induce inflammation around themselves on their own account, and, of course, render the pats close to them more ready to take on inflammation from cold. The "catching cold" superadds the chilblain. Now, when an important organ is inflamed, the consequences are of necessity severe; no langer to be compared in degree to the thorn and the chilblain. Let us briefly see what they are.

When a portion of any internal organ is inflamed, it becomes more full of blood, more solid, and the circulation cannot get on through it. The heart, finding a difficulty to push the blood through, works harder. Not only is the inflamed part a blood-obstructor, it is also a bloodspoiler. It acts as a bad gland acts in spoiling the quality of the blood. In a healthy body, the nutritive juices are helped into conversion into good blood as they pass through healthy glands ; but, if the glands be unhealthy, they convert these juices into unhealthy blood, and this is the essence of the constitutional disease, termed scrofula. Now, an inflamed organ acts in a similar way, for the time being, by damaging the quality of the blood which does not pass into and out of it. The damaged blood irritates the heart to still further excitement. The inflamed organ irritates the nerves, and through these telegraph wires a message is sent to every other part of the body, saying : "Much mischief is going on here, direct attention to it by disordering yourself"; and accordingly every other organ becomes disordered. The spinal cord sympathises and causes shivering, shuddering, gooseflesh, and perhaps chattering of the teeth. It is not desirable for the sufferer to move about, and so the limbs ache and are weak, and the back aches. It is not desirable for the mind to become much exerted, and so the brain is rendered unequal to effort, and there is headache. It is not desirable to take in much food, and so the stomach is deranged, and there is no appetite. It is desirable for the blood to pass as well as it can through the lungs, and so quickened breathing responds to the quickened pulse. And according to the degree of inflammation when it attacks the lungs, that is, of obstruction to the circulation through the lungs, there is a sense of want of breath. Shortness of breath always means that more blood is sent into the lungs than can readily be aërated and got through. When a healthy person runs himself out of breath, it is that he so quickens his pulse by exercise that more blood is sent into the lungs than can be purified and passed on. By rest, the circulation becomes quieter, and gradually no more blood is pushed into the lungs than they can accommodate. The lungs will only pass on blood that has been purified by aëration. If more be sent than can be aërated, it stagnates for the time, and the sense of want of breath becomes so urgent as to insist on being noticed and attended to. When there is quickened circulation and quickened breathing, more animal heat is generated. The body is burning itself up. To quell this, thirst arises.

Now, are all those serious derangements, or even the approach to them, compatible with feeling strong? On the contrary, they are attended by extreme weakness. Strength proceeds from the even, quiet, regulated performance of all the functions of the body and mind. From this excited disordered performance of all the functions, only weakness can proceed. When inflammation in the hand leads to the expulsion of the thorn, it is restorative and beneficial. When it is set up to expel a myriad of thorns, or seeds of disease from the lungs, it is usually destructive and injurious. So truly is the Divine law observed in disease, as in morals, that all evil is merely the perversion or the excess of that which, when kept withich proper limits and correctly controlled, is in itself good. Now, if infl xmmation be so great a danger to pulmonary invalids, can a climate which tends to produce inflammation be to such cases a strengthening climate? Can a climate which tends to keep inflammation away and to alleviate that which already exists be a weakening climate? In the so-styled fine bracing seasonable weather of a clear bright continued frost, when the cold sinks to seven degrees of frost (25 deg. Fahr.), from four to five hundred deaths are added every week to the bills of mortality in London alone. For cold is king, and, as the ephemeral insects of the sunshine are extinguished by the chill breath of night, so does he, when he locks the earth in his iron grasp, too of en ring the knell of the enfeebled, whether young or old! For the pulmonary invalid, therefore, the question is not, is a given climate bracing or relaxing? but is it cold, variable, and exciting, such as favours the oncome of inflammation? or is it soothing, mild, and anti.inflammatory? Were I to characterise the cllmate of Torquay, in a phrase, I would say it is sootbing and safe : safe because antiinflammatory; anti-inflammatory because mild and soothing. How often have I heard former visitors at Torquay say, "Torquay is the best place for anything of inflammation"; again, from another, "I never felt so strong anywhere as at Torquay"; again, "I never feel up to the mark at Torquay ; it is too relaxing for me". Now, the last remark always proceeds from one that has no organic disease; the other two remarks usually from those who have. Its soothing qualities are due to its mildness as to temperature ; to its equability of temperature between night and day; to the absence of the marked coldness at sundown, so common in other places; and to the invisible moisture in the air. For damp or visible moisture, I have nothing good to say, except that a sea-fog seldom does harm. People often inveigh against moisture in the air, as if an overdry air were not much more hurtful. Ask a New Yorker in his polar winter wind, the north-west- "the razor"-which answers to our east wind, when our polar current comes down to the earth-what he would not give for a breath of the soft south wind, with the balm of sea-moisture laden! At Torquay, all the moisture in the air is sea moisture, for we have no land water, and our geology is limestone, cropping up to the surface, which naturally drains away rainfall by the hilly cliffy character of the rocks. So long as this sea moisture is invisible, it makes the air soft and respirable, and it indicates a certain amount of heat in the air to enable it to render the contained moisture invisible. It diffuses a gentle haze through the air, which gives a Claude Lorrain softness of outline to the landscape, and acts in keeping in the heat like a fine thin cloud, radiating down again the heat which has been radiated up by the surface of the ground. Everyone knows that a cloudy night is a warm one ; a bright, clear, starlight night a cold one. By way of a personal illustration that seldom occurs, some years ago I had occasion to go without delay to St. Leonand's. It was in the second week of February. A bleak, quiet east wind was steadily on. I found it colder in London than at Torquay. I slept there, and next morning I found myself at the large hotel at St. Leonard's. Here the cold was bitter ; much more trying than in the Strand in London. I slept in London, and returned home the third day, the weather having been unchanged all the time. Below Bristol, the air became less cold. When I got out at Torquay, the cold was so much less unbearable that I took in long breaths, and mentally exclaimed, "Why, this is breathing made easy!" Now, consider what ease of breathing implies to a pulmonary invalid. It inplies in a word that his lungs are doing well.

There is one subject not strictly pertinent to the matter in hand, on which I wish to make a remark, because it is not commonly known, and it ought to be both known and appreciated ; and that is, that Torquay is peculiarly desirable as a residence for those who are prone to suffer from diseases of the kidneys, and from gout and goutishnessdiseases which are becoming not less rife in the land. Not so much because the town water is very soft and pure, being merely rain-water filtered through granite from the disintegrated felspar, of which it may derive possibly some inappreciable alkalinity, as because of the climate acting beneficially on the skin and on the mucous membrane, which is an internal skin.

In dysmenorrhœa and in stricture, alleviation is usually experienced from residence at Torquay. In a word, all ailments which depend 
upon chronic inflammatory irritation of any mucous membrane are benefited by this climate. Whereas general debility not so dependent, with an impoverished watery blood, dyspepsia, and atonic neuralgic affections are not.

The table I now show is copied by permission of the late Professor Daubeny from his own daily observations at Torquay in $186 \mathrm{r}$, and his assistants at Oxford, to show the greater amount of ozone in the air at Torquay. Greater amount of ozone means greater purity of air.

The second table represents the warmth of three places, as noted in my diary of the date of January 3 rd, 1867 -an unusually cold day. Cobham, Surrey, - 5 deg., or 5 below zero, 37 deg. of frost ; Bournemouth, 12 deg., or 20 deg. of frost; Torquay, 25 deg., or 7 deg. of frost.

\section{CLINICAL LECTURE}

\section{DISLOCATIONS OF MUSCLES AND THEIR TREATMENT.}

\author{
BY GEORGE W. CALLENDER, F.R.S., \\ Surgeon to St. Bartholomew's Hospital.
}

Gentlemen, - When M. Pouteau wrote "sur la luxation des muscles et sur leur reduction", he thought it necessary to give his reasons* for using the term luxation with reference to the accident he sought to describe. It expresses, however, so well the nature of the hurt, that no apology can be needed for now employing it.

It seems to me strange that one is still justified in saying with our author that the injuries to which I am now referring are but little known, and that we cannot to any large extent avail ourselves respecting them of the experiences of others; and although these hurts count as but a small detail in surgery, yet they are followed by considerable inconvenience, by pain often of long continuance, and interfering with just the very amusements or occupations in the following of which the hurt has been sustained, and the deprivation of which is often ill borne by the sufferer. Their chief interest to the surgeon lies in their diagnosis; for, when once he is able to make up his mind as to the nature of the hurt, he can be clear as to the treatment he should employ, and he will by experience be cautious as to his prognosis.

Now we all know how tendons are guarded by sheaths and are sheltered in grooves; and we are taught respecting some of them, that they are liable to be displaced from their natural bearings. $t$ Perhaps, of all tendons, those which have been most under notice are the biceps of the arm and the conjoined tendon, which, through the patella, comes occasionally to be dislocated from the front surface of the femur. There is Dr. Hamilton's case of supposed dislocation of the biceps tendon; and in our London museums there are specimens showing displacement of the tendon of this muscle. It is not long since a woman was under our notice in Sitwell Ward who suffered from a hurt of this nature. I am very sorry we could do but little for her; but we did not see her until long after the first occurrence of her trouble. This woman had great pain with her hurt. The shoulder seemed to droop forward; and she shrank from using the biceps, and, indeed, from moving the joint. The tendon lay on the inner side of its groove ; and, by pressing against it so as to push it out, and by rotating the arm inwards, it would slip back into the groove, but only to slip out again, when the pain, which had been for the time relieved, was again felt. Of course, continued rest was tried, in the hope that the tendon would be resheathed in its groove; but it was not so, and the conclusion we came to was that the groove had become in part flled up, probably by fibrous tissue; or that the tendon could not lie and act in it without some binding down by a sheath; and, as such ensheathing did not follow the reduction, the leader worked out so soon as any strain was brought to bear upon it.

The leaders about the wrist are not unfrequently displaced; and, unless the injury be early diagnosed (as it may te by recognising the irregular position of a tendon, to which attention is drawn by tenderness or by pain in working it), it will be, it is true, easy to reduce the dislocation, but it will be next to impossible to prevent its recurrence. It is only during the few weeks following the occurrence of the accident that the repair of the surroundings of the tendon has a chance of being perfected, and will be so efficiently completed as to insure absolute recovery from the hurt.

* Euvres Posthumes, t. ii, p. 177.

+ See, with reference to these dislocations, Dr. Wharton Hood On Bone-Setting, page 150 .
In treating trouble of this kind, the dislocation of the tendon should be promptly reduced; and the parts affected should be kept at rest for about four weeks, to give time for the repair of the surroundings of the leader. A little management in the case, for instance, of the wrist, will enable a given tendon to be rested without of necessity imposing absolute fixity upon the wrist or upon the many other tendons in front of and behind it; for, whilst taking every proper precaution, it is undesirable to fix unhurt tendons for any length of time, since by so doing they are apt to be rendered stiff and unfit for active work for many weeks.

One of the most troublesome cases I have lately seen was that of a man thirty-seven years of age, who slipped, and by a twist dislocated the two peronei from behind the external malleolus. When I first saw him, he had been, in truth, quite unable to get about for nearly two years. Nothing more could have been done for him during this time, as the tendons had been replaced, and the parts had been rested to give every chance of repair. Yet the tendons slipped out on the slightest provocation. We fitted this patient with an apparatus which prevented strain and lateral movement of the ankle, and with this he could walk well; but it is most probable he will often suffer from recurrence of the dislocation, whenever some strain finds the tendons unguarded by mechanical support.

Very troublesome, too, is the interference with the action of muscles which results from the dislocation of tendons consequent upon injuries to bones and joints. Their true bearings may be destroyed, and they have then to acquire new ones: a very slow process. These specimens from our museum illustrate this point. Sometimes you will see the tendon has.to wear for itself a groove through a projecting mass of bone; sometimes it is diverted to one side and is stretched, working at an awkward angle; and, worst of all, a tendon occasionally becomes wedged between two bones or two fragments of bone, and then its muscle is often prevented from acting. The most formidable of these injuries - and there are several examples of the hurt in our hospital museums-is when the femur is split through its condyles, and the patella drops into the cleft and is held there. It is very difficult to dislodge it. If it remain, it must result in loss of all movement in the joint. Formerly, it would scarcely have been thought right to interfere in such a case, and even now it must be considered a serious operation to ccin vert a simple into a compound fracture for the purpose of freeing a patella thus fixed, one the propriety of performing which could only be considered in exceptionally favourable cases.

Before referring to dislocations proper, let me mention to you a class of cases in which the sheath of a muscle is torn, allowing the muscle to protrude. We not unfrequently meet with these hurts. The muscles of the front wall of the abdomen suffer in this way, and a considerable protrusion of muscle results, sometimes forming a tumour, which is liable to be taken, on a superficial examination, for protrusion of some of the abdominal contents. There is a boy now in Harley Ward who, whilst running, slipped, and made a violent effort to recover himself. The fascia on the tront of the right thigh gave way, and the muscles which it should have restrained started forward. Now, although the parts were kept at rest by a long splint, the fascia never united, and the limb remains weak-weak, that is, in such movements as call for a strain upon the extensor muscles.

Such cases are by no means rare, nor, I believe, are dislocations proper of muscles. Those who suffer from these hurts will tell you they have "ricked" a part (the term sprain is usually used when joints are implicated), and the "rick" will have been referred to some muscle or group of muscles.

Now think how muscles are placed: packed in an orderly fashion; closely applied one to another; firmly held in place by ensheathing tissue, and yet so free as to allow their varied movements to be easily practised quite independently one of another; and often side by side are placed muscles which so act that, whilst one is in contraction, its neighbour is quiescent or is antagonistic. Suppose that one of the muscles for the flexion of the toot (I use here the illustration of Peuteau) contracts alone or with more violence than do its fellows, it is likely -is it not?-by the irregularity of this contraction, to be jerked out from its normal relations with adjacent muscles; and it cannot return to its natural position without some artificial aid. With no muscle is this accident more likely to happen than with those concerned in the varied movements of the spine. Here are in play muscles which act at varying angles, packed in close array; and these, with sudden or with disorderly movements of the parts, are perhaps of all most liable to be compressed out of their natural lines. Slender muscles--those of small size placed amidst others of greater magnitude -are of course the ones more readily displacted; whilst large masses of muscle, such as the glutei, are, from their bulk and their connections, evidently less, if at all, liable to be dislocated. 